\title{
Performance Appraisal and Employee Development in the University of Education, Winneba, Ghana
}

\author{
Moses Segbenya ${ }^{1} \&$ Ernest Osei Bonsu ${ }^{2}$ \\ ${ }^{1}$ Department of Business Studies, College of Distance Education, University of Cape Coast, Ghana \\ ${ }^{2}$ Pharmacy de Pabloe Ltd., Winneba, Ghana \\ Correspondence: Moses Segbenya, Department of Business Studies, College of Distance Education, University \\ of Cape Coast, Ghana. E-mail: moses.segbenya@ucc.edu.gh
}

Received: April 12, 2019

doi:10.5539/ijbm.v14n8p83
Accepted: May 10, 2019

Online Published: July 7, 2019

\begin{abstract}
The study examined performance appraisal (PA) and employee development in the University of Education, Winneba. The concurrent triangulation strategy or design from the pragmatic perspective was adopted for the study. A multi-stage sampling technique such as simple random, stratified and purposive sampling techniques were used to sample of 159 from a population of 271 (comprising 61 senior members and 210 senior staff) administrative staff of the University of Education, Winneba. Data collection instruments were questionnaire and unstructured interview guide. Quantitative data was analysed with frequencies, percentages, means and standard deviations, and Pearson correlation matrix. Pattern matching was used to present the qualitative data after coding and thematic analysis. The study found that administrative staff of the University were not satisfied with the present ranking PA method or system in vogue. Respondents strongly endorsed the need for 360-degree feedback PA system because it provides feedback from multiple sources and had a statistically positive significant relationship with employee development and performance. It was recommended that the management of the division of the human resource of the university should gradually phase out the existing performance appraisal system and introduce the 360-degree feedback performance appraisal system.
\end{abstract}

Keywords: performance appraisal, employee development, 360-feedback appraisal

\section{Introduction}

Providing feedback in the workplace has been a critical function of almost every organization that considered its employees as assets rather than liability. It is for this reason that the entire process of evaluating employee performance is among the important human resource (HR) functions or practices that remains one of the most heavily researched topics human resource management (Fletcher \& Perry, 2002). Performance appraisal (PA) has at least six main relevance to every organization that pays attention to it. These are identifying training needs, improving present performance, improving communication, improving motivation, disciplinary documentation and determining pay (Sefenu \& Nyan, 2017). Its key relevance is that it forms part of the salient activities and core functions that the human resource manager in an organization exists to perform. It therefore means that appraisal provides a linkage between all other human resources functions.

The traditional approaches of assessing performance of employees have been the ranking, paired comparison, grading and checklist techniques. These traditional methods only vest powers (the utmost authority) in managers and heads of departments or immediate supervisors to assess individual employees on their jobs. Based on these relationships between managers/heads and their employees, assessment results may be tilted away from the actual performance. In almost all the traditional method, the employer or the manager has an overriding authority since the employee is and can only be appraised by the employer or manager. The judgements from superiors may sometimes be based on errors such as stereotyping, biases and prejudice from previous actions to the detriment of the actual performance exhibited on the job. In such an environment, the employer or manager may see an employee as 'an enemy' and as such the personal development of the employee will be absent in the "good books" of the superior.

The challenges associated with the traditional methods of appraising employees has led to the introduction of the modern methods of performance appraisal (Segbenya \& Ahiatrogah, 2018) such as management by objective technique, behavioural anchored rating scale, human resource accounting, assessment centres and the 360-degree 
feedback (Deb, 2006; Bhattacharyya, 2011). The 360-degree feedback, the focus of this study is generally described as having the characteristic of being more employee centered as compared to the traditional ones that focused much on superiors only. The 360-degree feedback as a key variable in the modern methods of performance appraisal promotes genuineness and fairness. The 360 -feedback approach solicits information from multiple sources in attempt to provide accurate picture of the contributions of an employee to the development of the entire organization. It is one of the numerous appraisal approaches with which employers can assess the performance of their individual employees in this modern day.

The 360-degree feedback approach has been advocated as impacting positively on both individual and organizational performance (Valle \& Bozeman (2002). Daft (2008) therefore identified the 360-degree feedback as a powerful method to improve the quality of employees, as well as leadership and management in organizations. The 360-degree feedback method of appraisal assesses employee performance from several angles; peers, customers, self, supervisors and subordinates. Normally the ratings are collected and collated by an external consultant or by an internal human resource department to aid in effective decision making (Uma, Obidike, \& Ogwuru, 2013). Development in the life of an employee involves the ability of the individual to acquire, explore and utilize knowledge acquired onto the job. Employee development refers to the enhancement of skills, knowledge and experience of employees with the purpose and intention of improving their performances (Price, 2007). It involves putting measures in place as an employer to improve the knowledge, skill and abilities of employees in the any organization. The development of staff in every department, one way or the other, lies on the head of that department or supervisor of the employee. All staff members under supervision of a superior need to be assessed to know their how their level of output on the job stand.

Through various assessments of contributions made by individual employees with respect to the objectives of the organization, certain information and decisions might be exposed to the employer or manager, whether that individual needs training, promotion, transfer, counselling or need extra resources to work effectively. For these and many other reasons, the area of individual performance appraisal remains imperative to the development of almost every organization for which the University of Education, Winneba is not an exception. The University of Education, Winneba still uses the traditional method of performance appraisal to assess her administrative staff. Meanwhile, the traditional method of appraisal is characterized with the high possibility of supervisors/managers committing errors such as biases, stereotyping and prejudice in their decisions to the detriment of the actual performance of individual employees. It is possible that in certain cases of appraisal, some superiors could use performance appraisal as punishment tools and therefore hinders the development of employees in the work setting. The challenge of possible favoritisms on the part of evaluators can de-motivate talented employees and affect the productivity of the institution and at the end, a wrong performance evaluation which could damage the image and the reputation of the university.

Thus, the need for the multi-ratter which is holistic and satisfactory is more urgent than before. The needs for administrators to constantly upgrade their skills and knowledge required in performing modern day tasks could likely be absent since the institution still uses the traditional appraisal method to appraise it administrative staff. It is in this light that this study sought to examine the existing performance appraisal of UEW and the need for the 360-degree feedback (the modern appraisal) type for assessing the administrative staff of the university. This thus necessitated the formulations of three research questions and one hypothesis of the study. These are:

a) What performance appraisal systems are used in UEW?

b) How satisfied are employees with the existing performance appraisal systems in UEW?

c) What are the perceptions of employees on the need for 360-degree feedback?

\subsection{Hypothesis of the Study}

$\mathrm{H}_{0}$ : There is no significant relationship between the 360- degree feedback approach and employee development. $\mathrm{H}_{1}$ : There is a significant relationship between the 360- degree feedback approach and employee development

\subsection{Theoretical and Conceptual Perspective on Performance Appraisal and Employee Performance}

Goal setting theory has been used as the theoretical bases of this study. Goal-setting theory propounded by Edwin Locke examines the effects of setting goals on employees' job performance (Locke \& Latham, 2006). Goals achievement or attainment of targets set for employees is very core to the whole process of performance appraisal which is the focus of this study. The goal-setting theory argues that specific and challenging goals with appropriate feedback contribute to improved performance among employees. Criteria for effective goal that drives performance include goals being achievable, relevant and time-bound, illicit commitment and ensure task complexity. 
More specifically, targets/objectives or goals to be achieved direct the employees and enhances the employees in understanding the amount of energies/exertion required to put into their jobs to achieve their targets or the organization al goals within the short, medium- and long-term (Lunenburg, 2011). Specific goals can boost motivation and performance by leading employees to focus their attention on specific objectives. Employees then put in extra efforts to develop new strategies to face complex challenges to goal attainment (Latham \& Locke, 2006). Thus, goal-setting theory together with performance management systems impacts employee performance. The outcomes act as input for setting the next level of goals. This process can be repeated in a cycle to improve the performance of the employee (Appelbaum, Roy, \& Gilliland, 2011).

This theory is very relevant for this study because it discusses the link between performance appraisal and employees' performance. The relevance can be seen with regards to the need for setting target for administrative employees of the University against which they would be appraised. Secondly, the need to align staff personal goals into the organizational goals so that the two can be achieve either directly or indirectly. Nature of the goals has a lot of impact on what appraisers of the administrative staff of the university should take into consideration if they really want the appraisees to achieve their targets or the organizational goals within specified time. Meanwhile, the involvement of appraisees from the beginning of the appraisal process and the need to give feedback to the appraisees has also been indicated by the Goal setting theory to be very key in ensuring that appraisals enhance employees' performance among administrators of the university.

\subsection{Conceptual Discussion on Performance Appraisal and Employee Performance}

Performance appraisal is a formal process of evaluating organizational members including establishing of performance standards, appraisal related behaviours of ratters, determining performance rating and communication of the rating to the employee under scrutiny (Debrincat, 2015). The primary focus of all appraisals is to measure the actual performance of the employee and to perceive the areas of flaws on the part of employees. Although the relationship between appraisals and performance may not be a direct and causal one, their influence on performance may be attributed to their ability to enhance role clarity, communication effectiveness, merit pay and administration, expectancy and instrumentality estimates, and perceptions of equity (Yehuda, 1996). Factors that contribute to poor performance appraisal to include inadequate knowledge of appraisal systems; unclear performance standards, lack of inputs from staff in designing assessment tools thereby staff perceiving the whole process as unfair and ratter biased; lack of feedback to employees; inadequate training to both staff and supervisors on the appropriate design and use of the appraisal tool (Scullen et al., 2005).

Sias, P.M. (2013) argued that traditional performance appraisal methods such as forced ranking, the graphic ration scale, ranking methods, the checklist and critical incident methods, have become very ineffective over time and have been confronted with poor performance appraisal challenges. Curbing these challenges associated with the old performance appraisal methods call for the modern method of performance appraisal. Debrincat (2015) argues that adopting some modern methods such as Behavioural Anchored Rating Scale (BARS), assessment centres, Management By Objectives (MBO) as well as the 360 degree feedback approach looks to take away the negative aspect and errors of the some of the old methods of evaluating staff such as the biasness, stereotyping and some other common errors. The 360-degree feedback appraisal method (also called multi-source or multi-ratter feedback) which is the focus of this study is one of the modern appraisal methods which solicits feedback from a variety of sources including superiors, peers, self, subordinates, customers and suppliers (Herold \& Parsons, 1985). These different constituencies are believed to be a source of rich and useful information. For example, a subordinate's perspective is likely to be distinctly different from that of a customer or peer. The 360-degree feedback performance appraisal is often linked to evaluative purposes and has consequences for distribution of rewards, merit increase, promotions, and layoff decisions (Atwater, Brett, \& Charles, 2007).

Sias (2013) argued that there are several benefits that 360-degree feedback brings to organization s. The author identified benefits such as all-round development of the person being rated, coordination of all efforts towards achieving organization al objective; increased consistency in the performance, improved superior-subordinate relationships, helps create happy employees and helps to improve customer service (Sutherland \& Dodd, 2008). All these benefits can ultimately be responsible for career development and improve performance of organization (Zafft et al., 2009).

\subsection{Human Resource Development}

Human Resource Development (HRD) or employee development used in this study as the dependent variable, has been identified as one of the key variables in the human resource management process. It is considered a broad aspect of the entire management process which has been defined and explained in various ways and by 
experts according to how they perceive, utilize and their experiences from the HRD process. HRD focuses on training and development, career development and the entire development of the organization. HRD process can an integrated process of training and development, career development and organization al development to improve individual and organization al effectiveness.

Employee Development focuses on bringing the skill, knowledge and capacity levels of individual employees up to levels required to be exhibited on the job in achieving greater outputs. Training is a planned intervention that is designed to enhance the determination of individual job performance, when the individual functions independently or as a member of a team (Mathis, Jackson \& Valentine, 2014). Training and development therefore involve a process through which relevant programmes or initiatives that seek to address the needs of employees in their work environment presents a platform to learn and improve on performance exhibited on the job.

\subsection{Conceptual framework}

Figure 1 describes the conceptual framework of the study. In the framework, the 360-degree feedback approach is described. As depicted in the figure, 'Self' refers to the individual under appraisal, 'Emp' represents the input from employers and managers, 'Cus'represents inputs from customers, 'Sub'represents inputs from subordinates, whereas 'Peers' represents inputs from colleagues on the actual performance and behaviours exhibited on the job. These represent the various sources of information in terms of appraisal of employee under the 360-degree feedback.

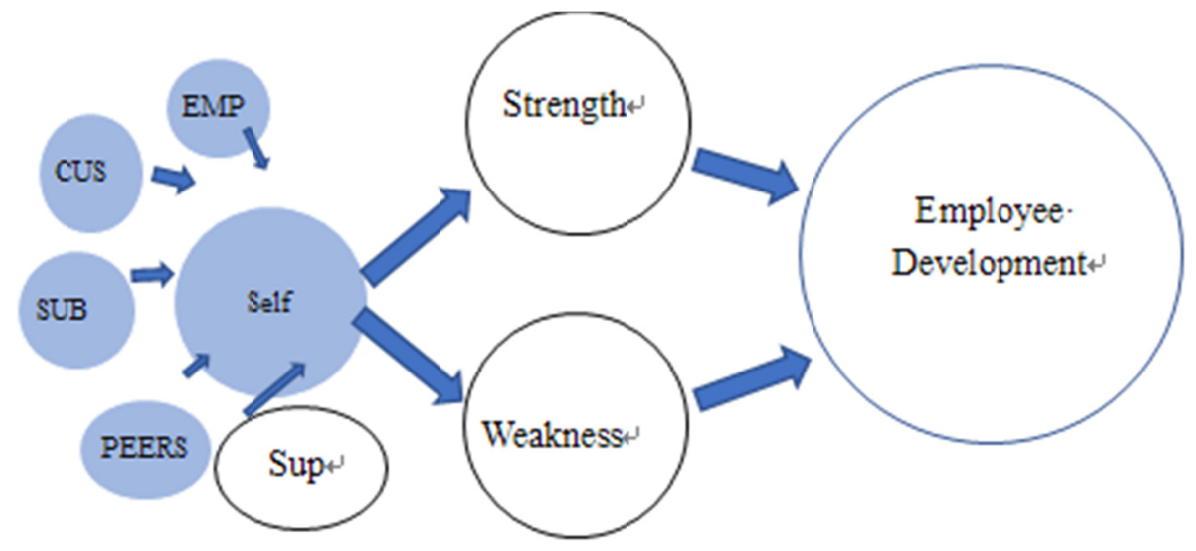

Figure1. Conceptual framework

The 360-degree feedback presents views from multiples sources on how work is carried out by an individual and how he/she relates to workmates, superiors, suppliers, and subordinates among others. This information gathered may present to employers and managers, the strengths and weaknesses attributed to specific individuals at a point in time. This information gathered is crucial and is very critical to decisions made by managers and employees regarding employees. It informs manager and employers to put in measures to promote, maintain and stimulate positive efforts of employees towards the achievement of organization al goals. Strength of employees are therefore encouraged by employers and managers through effective communication, assignment of new roles that comes with power, establishing clear performance metrics and making employees accountable for their deliveries, creating growth opportunities and leveraging the performance reviews to gain insight into the goals and aspirations of employees (Bajac, 2013). On the other hand, feedback from the 360-degree performance appraisal approach informs managers and employers on the deficiencies that surround an employee with respect to contributions and behaviours that affect their work life. It provides an avenue to uncovering the set-backs in performance through information from multiple sources.

Employee development remains the ultimate in sustaining and maintaining the positive efforts of employees as well as putting in place corrective measures to ensure the weakness and downsides of employees are upheld among top performers. Feedback from the 360-degree feedback process informs managers on what an employee lacks in terms of the needed skills, knowledge, materials and equipment for successful execution of task. Information from this feedback informs training programmes, aimed at developing the skills, knowledge, talent and abilities, hence explaining the framework above. 


\section{Method}

The study employed the concurrent triangulation strategy or design from the pragmatic perspective. Creswell (2009) defines the concurrent triangulation strategy as a study where the researcher collects both quantitative and qualitative data concurrently and then compares the two databases to determine if there is convergence, differences, or some combination. Thus, this design uses separate quantitative and qualitative methods to offset the weaknesses inherent within one method with the strength of another.

The population of the study comprises two hundred and seventy-one (271) non -academic staff who were in senior staff and senior member position in the UEW as at 2017 (61 senior members and 210 senior staff) (UEW, 2016). A sample of one hundred and fifty-nine (159) staff was drawn using Krejeie and Morgan (1970) table for determining samples. The stratified, simple random sampling techniques were used for senior staff administrators paying attention to the various categorization within this group of staff, and lastly the purposive sampling techniques was used for senior member administrators.

This study employed questionnaire and interview guide for eliciting information from respondents. The questionnaire was pre-tested to test the validity and reliability of the instruments and to ensure that all elements of ambiguity have been removed. A Cronbach alpha value of 0.685 was obtained after the test for the reliability was conducted. Data collection (both quantitative and qualitative) was done from April 2017 to July 2017. The questionnaire was self-administered to respondents after the purpose was explained to them. There were follow-ups and reminders to encourage respondents to answer the questionnaire which resulted in 73 per cent response rate. Respondents' demographic characteristics and research question one was analysed with frequencies and percentages. Research questions two and three were also analysed with means and standard deviations. Finally, the hypothesis of the study was analysed using Pearson correlation matrix. Pattern matching of thematic content analysis was used to analysed the qualitative data collected for the study.

\section{Results and Discussion}

This chapter discussed the findings of the study on the general perception of employees on the current appraisal systems in place, the need for the 360-degree feedback and show it relates to the overall development of employees in the University of Education, Winneba. Analysis and result reported in this section are in two-man parts such as employee's demographic/bio data and results for the main research questions and hypothesis of the study.

\subsection{Bio Data of Respondents}

Bio-data of respondents discussed in this first part of the results and discussion are age, sex, working experience, ranks (as shown in Table1) and highest educational level (see Figure 1). It can be seen from Table 1 that $55.2 \%$ of 116 were male, whereas the remaining $44.8 \%$ constituted females. This clearly shows males administrators were dominant among the senior staff category in the University of Education, Winneba. In terms of age of respondents, majority of respondents $(36.2 \%)$ were 40- 49 years followed by workers who were 30-39 years constituting $31 \%$. This revealed that the university had approximately $88 \%$ of its senior staff in their youthful ages and for that matter had an energetic work force ready to work and give of their best in terms of work output. Table1 also reveal that majority of the administrative staff of the university had worked for 2-4 years (38\%) followed by those who worked for less than a year (23\%). This means that majority of the administrative staff of the university have worked for less than five years and this has impact on performance and retention intentions since employees with few years of working experience are more likely to leave their organization /s.

Table 1. Demographic characteristics of respondents 


\begin{tabular}{llcc}
\hline & Biodata & Frequency & Percentage \% \\
\hline Sex & Male & 64 & 55.2 \\
& Female & 52 & 44.8 \\
Age & Total & 116 & 100 \\
& $20-29$ & 24 & 20.7 \\
& $30-39$ & 36 & 31 \\
& $40-49$ & 42 & 36.2 \\
Years of working experience & $50-59$ & 14 & 12.1 \\
& Total & 116 & 100 \\
& Below 1 year & 23 & 38 \\
& $2-4$ & 44 & 17 \\
Rank & $5-9$ & 19 & 22 \\
& 10 & 26 & 100 \\
& Total & 116 & 24.1 \\
& AA & 28 & 57.8 \\
& SAA & 67 & 7.8 \\
& PAA & 9 & 10.3 \\
& CA & 12 & 100 \\
& Total & 116 & 18 \\
& Diploma & 21 & 75 \\
& Bachelor's Degree & 87 & 7 \\
& Post Graduate Diploma & 8 & 100 \\
\hline
\end{tabular}

Source: Field data (2017).

There were more respondents in the Senior Administrative Assistant's (SAA) rank (57.8\%) categorisation followed by administrative assistants (AA) (24.1\%) rank categorization. The last demographic characteristic of concerned was the highest educational level of respondents and it can be seen from Table 1 that most of the respondents were bachelor's degree certificate holders, and this has a positive impact on trainability and performance of the employees and organization .

3.2 Examining the Existing Appraisal System for Senior Administrative Staff of the University of Education, Winneba

This section focuses on examining the existing performance appraisal system used by the university to evaluate its administrators. Table 2 shows results for respondents' level of agreeableness or disagreeableness on items forming the existing appraisal system used for administrative staff of the university.

Table 2. Respondents assessment of existing appraisal system in UEW

\begin{tabular}{lllll}
\hline Response & & Agree & Disagree & Total \\
\hline Knowledge of Specific Appraisal Type in UEW & No & 72 & 44 & 116 \\
& $\%$ & 62.1 & 37.9 & 100 \\
Appraisal in the department is only done annually & No. & 104 & 12 & 116 \\
& $\%$ & 89.6 & 10.4 & 100 \\
Usage of one-on-one interview for PA & No & 25 & 91 & 116 \\
Employee taking part in Performance Appraisal & $\%$ & 22 & 78 & 100 \\
& No & 35 & 81 & 116 \\
Colleagues assess peers & $\%$ & 30.2 & 69.8 & 100 \\
Superior assessing subordinates & No. & 23 & 93 & 116 \\
\hline
\end{tabular}

Source: Field data (2017). 
Results as revealed in Table 2 indicates that majority (62.1\%) agreed that they had some level of knowledge on the existence of performance appraisal systems whiles $37.9 \%$ indicated otherwise. With regards to the specific type of appraisal system in place, respondents could not specifically indicate it. Lack of knowledge on the specific type of PA system used was further corroborated by interview data gathered from one of the four senior members interviewed who indicated that:

"The type of performance appraisal method that is adopted by UEW can't specifically spelt out, but for sure, there are some in existence. Every institution set up under law is mandated to conduct performance appraisal for its staff. UEW was also set up by the PNDC law 322, which makes it legitimate to have and conduct appraisal for its staff, but as to the specific type, method or approach adopted, I cannot name it" (SMA, 2017).

This is a clear indication that the exact type of PA system used in UEW was not clear to respondents. That notwithstanding, a senior member at the Division of Human Resource was emphatic and specific with regards to type of PA system used to appraise administrative of the university. According to this respondent, the university uses the ranking methods in assessing the behaviours and output of staff in the departments. The interviewee further reiterated that most employees including senior members had little or no information on issues of performance appraisal used. This suggests that the division of human resource of the university was not educating these respondents on PA systems including the type used by the University.

The type of stakeholder who does the appraisal was also considered as part of the results as shown in Table 2 . The table indicates that majority of the respondents $(96.6 \%)$ agreed to the statement that they were appraised by their superiors. This further confirms the statement on "colleagues appraising peers" which majority of respondents $(80.1 \%)$ disagreed with the statement. This could lead to the possibility that employees in the good books of the superior could be favoured and the vice versa as found by Deb (2006). The results also mean that 360-degree feedback appraisal system, a modern appraisal method was not practiced by the university. The traditional appraisal method was still practiced by the university to evaluate the performance of administrative staff.

Information was elicited on how frequently performance appraisal was conducted in departments of respondents and it is clear from Table 2 that majority of respondents $(89 \%)$ consented that they were appraised at the end of every year (annually). Majority of the respondents also revealed that they were not consulted and were not part of the pre-performance appraisal process or planning $(69.8 \%)$ and there was lack of one-on-one interview or meeting between appraisees and appraisers before appraisal is conducted (78\%). This means that though there is enough time (12 months) for appraisees and appraisers however, the "wrong" associated with performance on the part of administrators could get worse before it is finally identified after the 12 months unless there are other methods of identifying these performance challenges. This assertion of administrative staff of the university was however, contested by the senior members interviewed. Respondents interviewed indicated that appraisers were always encouraged to engage the apprises in the process. These respondents were very much convinced that some appraisers could have been doing the right thing but also alluded to the fact that since it was a human institution, some appraisers could have also done otherwise. The results mean that appraiser controls the whole process in terms of quality, how and when of the appraisees.

The results confirm the assertion by Debrincat (2015) that inadequate knowledge of appraisal systems sometimes yield disappointing results because of unclear performance standards, lack of inputs from staff in designing assessment tools making staff to perceive the whole process as unfair and the ratter biased. The result also further confirms the findings of Boateng (2011) that lack of feedback to employees; inadequate training to both staff and supervisors on the appropriate design and use of the appraisal tools is an indication that the PA system may not be effective.

\subsection{Satisfaction Level of Existing PA System among Administrative Staff of UEW}

The second research question measured the satisfaction level of administrative staff with regards to the existing PA system practiced by the University. The analysis for this research question was done with means and standard deviations as can be found in Table 3. The results in Table 3 show that administrative staff of UEW were not satisfied with existing performance appraisal systems based on the mean values obtained for the ten individual items in the table. The group Mean $(\bar{x})$ for the statements revealed that common responses to items were unfavourable. The results indicated a Mean and a Standard deviation on the satisfaction level of employees on existing performance appraisal systems as $(\bar{x}=2.44, \mathrm{SD}=0.363)$. According to the key for interpreting the results in Table 3 (Strongly Disagree $=1$; Disagree $=2$; Agree = 3; Strongly Agree = 4), the mean 2.44 is less than 3 and closer to 2, and for that matter, lies in the region of disagreement as responded by employees. This 
implied that respondents were not convinced and were not satisfied with existing appraisal systems adopted for the purposes of managing performances of individual employees in the University of Education, Winneba.

Table 3. Satisfaction of employees at existing performance appraisal systems

\begin{tabular}{lccc}
\hline Statements & $\mathrm{N}$ & Mean & Std. Deviation \\
\hline I prefer being assessed by my superior alone & 116 & 1.73 & 0.71 \\
Feedback are always communicated to employees & 116 & 2.13 & 0.7 \\
The purpose of the performance appraisal is clearly outlined and understood & 116 & 2.4 & 0.68 \\
I am satisfied with the current appraisal method in my department & 116 & 2.4 & 0.56 \\
I understand the whole process of evaluating my efforts & 116 & 2.48 & 0.5 \\
I am always informed when my performance is being appraised & 116 & 2.49 & 0.64 \\
The process of evaluating my output suits my expectations & 116 & 2.5 & 0.55 \\
I am pleased with how appraisal is conducted in the division/ department & 116 & 2.59 & 0.98 \\
Feedback is provided on my job to help improve my performance & 116 & 2.75 & 0.57 \\
This process helps me in finding out my actual level of performance & 116 & 2.98 & 0.66 \\
Total Average & & 2.45 & 0.363 \\
\hline
\end{tabular}

Key: Strongly Disagree = 1; Disagree $=2 ;$ Agree $=3 ;$ Strongly Agree $=4$.

Source: Field data (2017).

The dissatisfaction for the ranking PA system currently used to appraise senior staff administrators of UEW was also confirmed in an interview with senior member administrators. A respondent indicated this in an interview that "I don't seem to know where we are going with this kind of assessment. How we carry out our appraisal does not provide feedback to employees and for that matter demoralise and affect their input of employees as a whole".

This is a further confirmation of dissatisfaction for the existing PA system. The result suggests the need for a more satisfactory method better than the existing PA system in vogue. It is for this purpose that the next section examined the perception of administrative staff of UEW on the need for the 360-degree feedback appraisal system. The result is in conformity with a study by Poornima and Manohar (2013), who concluded when workers are dissatisfied with existing PA system, it is a wakeup call for management to consider introducing a better PA system to ensure continuous performance.

\subsection{Perceptions of Employees on the Need for 360 Degree Feedback}

The last research question assesses respondents/administrative staff perception of the need for 360-degree feedback PA system and the results can be seen from Table 4. From Table 4, respondents overwhelmingly endorsed the need for the 360-degree feedback PA system. Almost all the 15 items (except one item) items had a mean value above $\mathrm{M}=2.5$ which can conveniently be approximated to 3 which is interpreted to mean agreement. Other items also mean values which were more than 3 suggesting a very strong agreement to these items and an approval for 360-degree PA system. The group Mean (mean of means) was calculated to determine general perception of employees on the subject. The results in Table 4 indicated a group Mean and a Standard deviation $(\bar{x}=2.9, \mathrm{SD}=0.52)$ which also approximates to 3 and falls in the 'Agree' categoriasation of the scale as specified by the key. 
Table 4. Perception on the need for 360-degree feedback

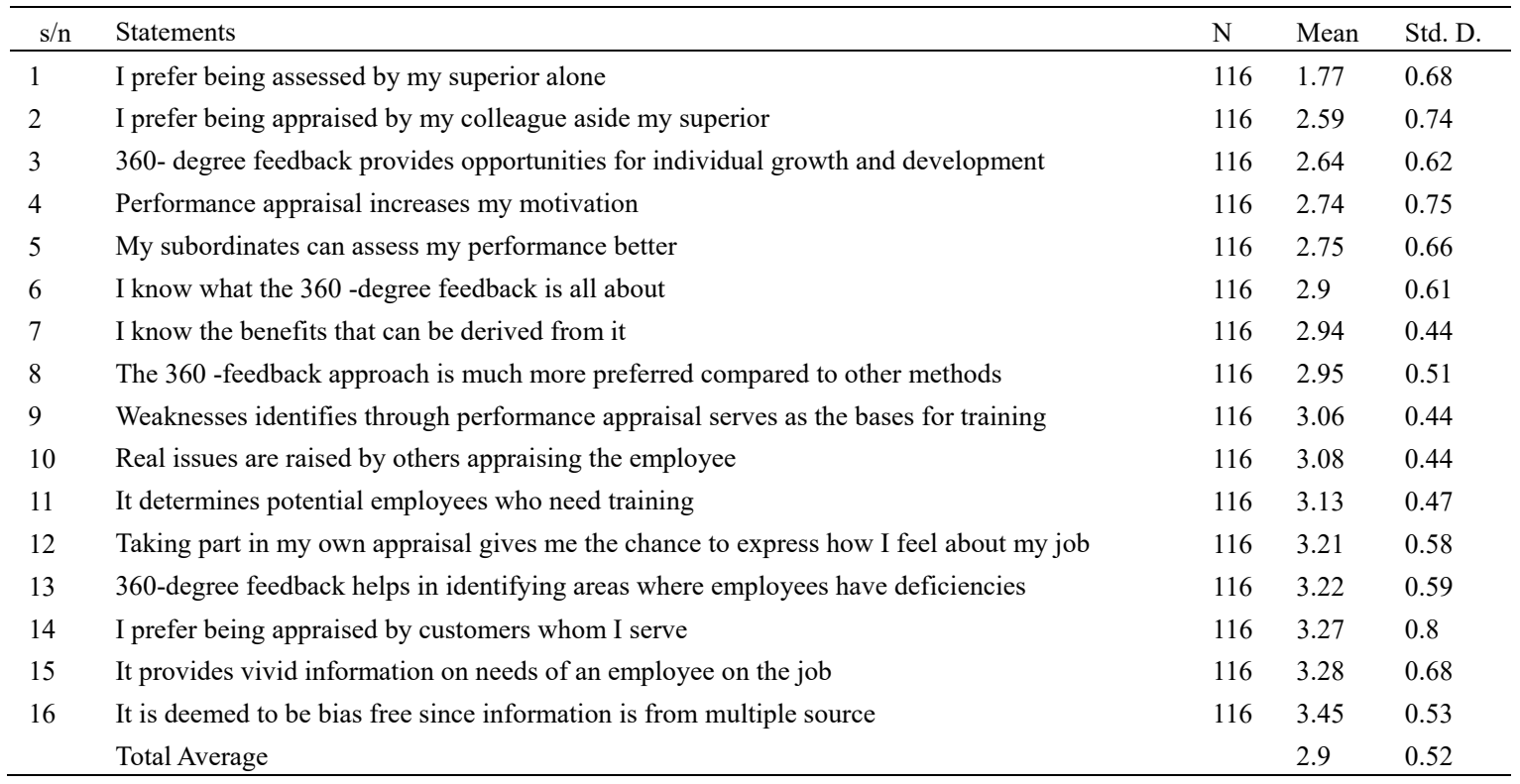

Key: Strongly Disagree $=1 ;$ Disagree $=2 ;$ Agree $=3 ;$ Strongly Agree $=4$

Source: Field data (2017).

The results means that respondents do not have problem with allowing all key stakeholders to appraise them which is called 360 degree feedback PA system, a component of a modern appraisal approach. These could comprise, superior, subordinate, peers, students (customenrs), suppliers among others. This method could give a more wholistic view on admistrators performance rather than what was in vogue which arrogates all powers to the superior. The findings agrees with the interview data gathered from senior members administrators. A widely held view shared by a respondents that "I think it is a step in the right direction to collect information about employees from others around him or her to complement that of the boss's" (SMA5, June, 2017) is a clear indication that the 360-degree feedback PA system was preferred over the PA system in vogue. This means that certain information gathered from multiple sources can help identify certain areas of key interest to the job performance hidden to the superior. This result support the finding of Sutherland et al (2008) that feedback from multiple sources could improve people's performance in a work team. The findings further support the conclusion of Zafft et al. (2009) that feedback is invaluable to the individual when it comes from numerous sources, providing multiple perspectives and opinions on the worker's performance.

\subsection{Hypothesis Testing}

The study hypothesised that:

$H_{0}$ : There is no significant relationship between the 360-degree feedback approach and employee development.

$H_{1}$ : There is a significant relationship between the 360-degree feedback approach and employee development

Pearson Correction matrix was used to test whether there was a relationship between the 360-degree feedback and employee development. A Pearson correlation analysis was conducted to test the only hypothesis of the study and the results can be seen from Table 5 . 
Table 5. Correlation Matrix on 360-degree feedback and employee development

\begin{tabular}{llll}
\hline Variables & & 360 Degree Feedback & Employee Development \\
\hline 360 Feedback Approach & Pearson Correlation & 1 & $.246^{* *}$ \\
& Sig. (2-tailed) & & 0.008 \\
& $\mathrm{~N}$ & 116 & 116 \\
Employee Development & Pearson Correlation & $.246^{* *}$ & 1 \\
& Sig. (2-tailed) & 0.008 & 116 \\
\hline
\end{tabular}

**. Correlation is significant at the 0.01 level (2-tailed).

Source: Field data (2017).

From the results presented by the correlation matrix in Table 5, there was a statistically positive, weak and significant relationship between 360-degree feedback appraisal system and employee development $(\mathrm{R}=.246$, Sig. $0.008, \mathrm{P} \leq 0.05)$. The result means that any percentage increase in 360-dgree feedback PA system would equally yield same percentage change in employee development in UEW. Based on the significance relationship established between development and PA system, the study thus accepted the alternative hypothesis that; there is a significant relationship between the 360- degree feedback approach and employee development

Interview data from senior members administrators equally revealed their support for the 360-degree feedback PA system in the university. This was indicated in an in-depth individual interview and widely held view by an interviewee indicated that:

"I think the multi-ratter approach [360-degree feedback PA] can be a major source to developing individual employees. This is because a variety of people gets the opportunity to put an employee on the stand and assess their efforts. I think deficiencies in terms of employees' ability to performing his/her job can be known and addressed through training and other developmental opportunities" (SMA2, June 2017).

Getting feedback from diverse group of stakeholders on an administrator's performance can therefore confirm or deny what just a superior might find. For this reason, this respondent fully endorsed it and concluded that deficiencies identified could lead to training and development. This could make the 360 -degree feedback PA system very instrumental in identifying training and development needs of administrators before training and development programmes are designed for training them to overcome their deficiencies.

The results are further corroborated by another senior member administrator who said that:

"It is a great platform for an employee to know how well others think about their performance at the workplace and on the job as well. The development bit comes in when employee is not performing up to the standards. Information from the multi-ratter approach can therefore serve as a source document to initiating a need analysis in the training and development process. Therefore, since the individual development goes a long way to affect the development of any organization, I think it's a something all managers, employers and employees must pay close attention to" (SMA4, June 2017).

This is a clear indication of total support for the 360-degree feedback PA system because of the advantages it has over the existing traditional appraisal method in vogue. This respondent equally liked the PA to training and development needs assessment or analysis. This further indicate and confirms that PA outcomes are not an end in themselves but a means to enhance to skills and competencies of administrators of the University for better performance.

\section{Conclusion and Recommendations}

The study found that there was performance appraisal system in place for administrators in the university, however, the exact type of performance appraisal used to assess administrators was not readily known by the respondents except the division of human resource. This implied that employees were ignorant of the specific appraisal system used in assessing their performance. Employees may be affected one way or other, especially when employers and superiors have the utmost authority to assess and evaluate the performance of employees.

It was also found that respondents were not satisfied with the present PA system which was the ranking method. Both respondents for questionnaire and individual in-depth interview were not happy with PA system which suggest the need for a more encompassing and modern PA system that will be beneficial to respondents. Respondents strongly endorsed the need for 360-degree feedback PA system as against the traditional ranking PA system in place. Respondents' desire for the 360- degree feedback was because it has the propensity of 
providing feedback from multiple sources which could improve people's performance. Performance appraisal was found to have statistically positive significant relationship with employee development and performance. This means that development programmes for administrative staff of the UEW are strongly linked to performance appraisal since it has the ability of identifying training needs, compensation level and promotion. Thus, investment in the right type of performance appraisal could lead to same return in employee development.

The above conclusions indicate a need for certain action to take place by management. It is therefore recommended that the management of the division of Human Resource, University of Education, Winneba, should:

1. Gradually phase out the existing performance appraisal system and introduce the 360-degree feedback performance appraisal system. The latter has the advantages of holistically assessing employees from the perspectives of all key stakeholders such as customers, suppliers, superiors, subordinates and peers among others.

2. Educate administrative staff of the university on the benefits of the 360-degree feedback performance appraisal system. This could be done through workshops, seminars or encouraging appraisers to explain this to their appraisees.

3. Encourage appraisers to involve employees in the performance appraisal process since it has the propensity of suggesting to appraisees that the performance appraisal system is fair.

\section{References}

Appelbaum, S. H., Roy, M., \& Gilliland, T. (2011). Globalization of performance appraisals: Theory and applications. Emerald Group Publishing Limited, 6(22), 570-585. Retrieved July, 2017 from https://www.emeraldinsight.com/doi/abs/10.1108/00251741111126495?src=recsys\&journalCodem

Atwater, L. E., Brett, J. F., \& Charles, A. C. (2007). Multisource feedback: Lessons learned and implications for practice. Journal of Human Resource Management, 46(2), 285-307. Retrieved from https://asu.pure.elsevier.com/en/publications/multisource-feedback-lessons-learned-and-implications-for-pr actic

Bhattacharyya, D. K. (2011). Performance management systems and strategies. India: Dorling Kindersley. Retrieved from https://www.arabianjbmr.com/pdfs/Om_Vol_5_(1)/2.pdf

Boateng, E. (2011). Effects of PA on the achievement of organizational objectives. (Masters Dissertation, Kwame Nkrumah University of Science and Technology). Retrieved from http://ir.knust.edu.gh/bitstream/123456789/4514/1/Eric\%20 Boateng.pdf

Creswell, J. W. (2009). Research design; qualitative, quantitative and mixed methods approach. California: Sage Publications

Daft, R. L. (2008). Management (8th ed.). Thomson learning: South Western. Retrieved from https://www.academia.edu/38127481/Management__Richard_L._Daft

Deb, T. (2006). Strategic approach to human resource management: Concept, tools and application. New Delhi: Atlantic Publishers and Distributers. Retrieved from https://www.academia.edu/29615541/Strategic_Human_Resource_Planning

Debrincat, G. (2015). The effectiveness of performance appraisal systems: Employee relations and human resource management. Retrieved from http://search.ebscohost com/login.aspx?

Fletcher, C., \& Perry, E. L. (2001). Performance appraisal and feedback: A consideration of national culture and a review of contemporary research and future trends. London: Sage. Retrieved from http://sk.sagepub.com/reference/hdbk_orgpsych1/n8.xml

Herold, D. M., \& Parsons, C. K. (1985). Assessing the feedback environment in work organizations: Development of the job feedback survey. Journal of Applied Psychology, 70, 290-305. Retrieved from http://dx.doi.org/10.1037/0021-9010.70.2.290

Locke, E. A., \& Latham, G. P. (2006). New directions in goal-setting theory. Current Directions in Psychological science, $\quad$ 15(5), 21-36. Retrieved from https://home.ubalt.edu/tmitch/642/Articles\%20syllabus/locke\%20latham\%20new\%20dir\%20GS\%20curr\% 20dir\%20psy\%20sci\%202006.pdf

Lunenburg, F. C. (2011). Goal-setting theory of motivation. International Journal of Management, 15(1), 1-5. 
Mathis, R. L., Jackson, J. H., \& Valentine, S. R. (2014). Human resource management (14th ed.). Stamford: Cencage Learning. Retrieved from https://core.ac.uk/download/pdf/33797590.pdf

Price, A. (2007). Human Resource Management in a Business Context (3rd ed.) London: Thomson Learning. Retrieved from http://www.dphu.org/uploads/attachements/books/books_4912_0.pdf

Scullen, S. E., Bergey, P. K., \& Aiman-Smith, L. (2005). Forced distribution rating systems and the improvement of workforce potential: A baseline simulation. Personnel psychology, 58, 132. Retrieved from https://www.academia.edu/24923102/Forced_Distribution_Rating_Systems_and_the_Improvement_of_Wor kforce_Potential_A_Baseline_Simulation

Sefenu, J. S., \& Nyan, K. (2017). Human resource management. Cape Coast, Ghana: University of Cape Coast Press.

Segbenya, M., \& Ahiatrogah, P. D. (2018). Appraisal of managerial roles of study centre coordinators of College of Distance Education, University of Cape Coast. World Journal of Education, 8(5), 1-16. Retrieved from https://scholar.google.com/citations?user=ftJJGDMAAAAJ\&hl=en

Sias, P. M. (2013). Workplace relationships (3rd ed.). Thousand Oaks, CA: Sage. Retrieved from https://www.researchgate.net/publication/233160384_Workplace_Relationship_Quality_and_Employee_Inf ormation_Experiences

Sutherland, A. M., \& Dodd, F. (2008). NHS Lanarkshire's leadership development programme's impact on clinical practice. International Journal of Health Care Quality Assurance, 21(6), 569-584.

UEW. (2016). Basic statistics for $20^{\text {th }}$ congregation; Second session. Winneba: UEW publications.

Uma, K., Obidike, P., \& Ogwuru, H. (2013). Revamping Nigeria education sector for quality manpower development. Journal of Social Issues and Humanities, 3(6), 330-339.

Valle, M., \& Bozeman, D. P. (2002). Interrater agreement on employees' job performance: review and directions. Psychological Reports, 90, 975-985.

Yehuda, B. (1996). Self-performance appraisal vs direct-manager appraisal: A case of congruence. Journal of Managerial Psychology, 11(6), 50-65.

Zafft, C. R., Adams, S. G., \& Matkin, S. G. (2009). Measuring leadership in self-managed teams using the competing values framework. Journal of Engineering Education, 98(3), 273-282. https://doi.org/10.1002/j.2168-9830.2009.tb01024.x

\section{Copyrights}

Copyright for this article is retained by the author(s), with first publication rights granted to the journal.

This is an open-access article distributed under the terms and conditions of the Creative Commons Attribution license (http://creativecommons.org/licenses/by/4.0/). 